\title{
Conditions to optimize mass production of Metarhizium anisopliae (Metschn.) Sorokin 1883 in different substrates
}

\author{
Lorena Barra-Bucarei ${ }^{1 *}$, Pedro Vergara ${ }^{2}$, and Amparo Cortes ${ }^{3}$
}

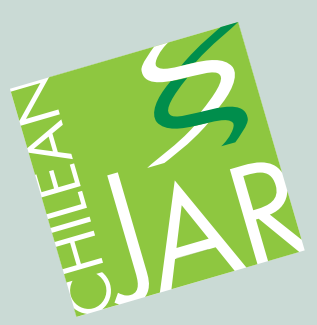

\section{ABSTRACT}

One of the best alternatives to reduce the amount of chemical insecticides released into the environment is biological agents. Metarhizium anisopliae (Metschn.) Sorokin 1883 (Hypocreales: Clavicipitaceae) is an entomopathogenic fungus with great potential as a biological pesticide to biologically control pests. However, the relatively high cost of the substrate needed for its mass production system increases product price and discourages its use. The objective of this study was to optimize the mass production conditions of M. anisopliae for use as a biological control agent using two solid substrates, new parboiled rice (NPR) and recycled parboiled rice (RPR). Conidial production was optimized by the response surface methodology (RSM). The effects of the temperature, time, and molasses variables and the interactions between them (conidia $\mathrm{g}^{-1}$ ) were determined. For the NPR substrate, it was determined that the significant variables were time and temperature, and the interactions were temperature $\times$ molasses and temperature $\times$ time. For the RPR substrate, the significant variables were temperature and time, and the interactions were time $\times$ molasses and temperature $\times$ time. Both substrates obtained the highest industrial yields at $25{ }^{\circ} \mathrm{C}$ for a period of $20 \mathrm{~d}$. Given that the percentage of molasses was not critical for yields, it is recommended that it be set at $5 \%$ to reduce costs. Finally, it was possible to use the RPR substrate from the $M$. anisopliae produ9ction itself as an alternative to solid substrate; mean industrial performance (conidia $\mathrm{g}^{-1}$ ) was higher than values obtained with NPR and at a lower cost.

Key words: Biological control, entomopathogenic fungi, mass production, optimization, response surface methodology.

${ }^{1}$ Instituto de Investigaciones Agropecuarias, INIA Quilamapu, Av. Vicente Méndez 515, Chillán, Chile.

"Corresponding author (lbarra@inia.cl).

${ }^{2}$ Universidad Tecnológica Metropolitana, Facultad de Ingeniería, Dieciocho 161, Santiago, Chile.

${ }^{3}$ Universitat de Barcelona, Facultat de Farmàcia, Joan XXIII 27, 08028, Barcelona, España.

Received: 22 June 2016

Accepted: 2 December 2016.

doi: $10.4067 /$ S0718-58392016000400008

\section{INTRODUCTION}

Biological insecticides are becoming increasingly relevant for safe, effective, and environmentally friendly pest control because of the harmful effects caused by chemical pesticides on the environment and human health. Metarhizium anisopliae (Metschn.) Sorokin 1883 is one of the best known entomopathogenic fungi; it is pathogenic to more than 200 species from different insect orders (Freimoser et al., 2005; Samson et al., 2013) and appropriate for commercial development. This fungus has the ability to directly penetrate the insect cuticle (Schneider et al., 2013) through combinations of mechanical pressure and cuticle-degrading enzymes (Beys-da-Silva et al., 2014). When attaching themselves to the body of a suitable host, conidia produce a germ tube, which through extension and growth give rise to hyphae that penetrate into and grow within the insect and causing its death.

Metarhizium anisopliae is commercially produced in solid substrates, but this type of production complicates process automation; it relies on batch production and does not provide a satisfactory economy of scale (Wraight et al., 2001). The twophase culture (liquid and solid) is the most commonly used technique to mass produce Metarhizium. Liquid fermentation is used to produce blastospore (Riaz et al., 2013) and mycelium forms (Pereira and Roberts, 1990; Kruger et al., 2014). The solid phase is carried out in a solid substrate, which has a large surface area for aeration and physically supports the fungus to produce conidia, and it is also used as a source of nutrients (Jenkins et al., 1998). Different substrates of vegetable origin can be used to mass produce conidia, such as different forms of potato, wheat, soy, rice, and bran. Studies by Dorta and Arcas (1998) show that rice is a good medium to mass multiply $M$. anisopliae because it provides nutrients and a large surface area on which conidia can be produced. Conidial production using rice as a substrate is approximately $1 \times 10^{9}$ conidia $^{-1}$ (Barajas et al., 2010). The most used solid substrate is parboiled rice (pre-cooked); it is very expensive (Kruger et al., 2014) and thus increases the final selling price. It is recommended that the objective of the production process be low cost and high yield of viable, virulent, and persistent propagules (Kassa et al., 2008).

The most important environmental factors that affect the mass production of Metarhizium anisopliae are temperature (Li and Feng, 2009; Chen et al., 2014), which is considered as a critical factor during the incubation stage (Elósegui, 2006), 
humidity of the solid substrate, which noticeably affects the sporulation process and is optimal between $57 \%$ and $58 \%$ RH (Arzumanov et al., 2005), pH, which needs to be slightly acidic in both phases to facilitate fungal growth and inhibit the growth of other microorganisms, and time (Kleespies and Zimmermann, 1992). In the mass production process, conidia are harvested $21 \mathrm{~d}$ after inoculation in the substrate; there have also been good results $14 \mathrm{~d}$ after inoculation (Rezende, 2009). One of the optimization methodologies that has been used in industrial processes is the response surface methodology (RSM); it combines mathematical and statistical techniques to build empirical models (Hanrahan and $\mathrm{Lu}, 2006)$. This methodology is advantageous because it allows identifying the effect of factors that generate a basis for additional experiments and setting values to factors that improve performance; this leads to savings in time, materials, and labor (Gohel et al., 2006). Therefore, the aim of this study was to optimize the mass production of Metarhizium anisopliae in different substrates.

\section{MATERIALS AND METHODS}

\section{Strain and culture conditions}

The selection of Metarhizium anisopliae was based on work by France et al. (2000) in which the inoculum was obtained by growing the fungus in potato dextrose agar (PDA) and incubating it at $25 \pm 2{ }^{\circ} \mathrm{C}$ for $15 \mathrm{~d}$. Microscopic examination of fungal isolates resulted in the preliminary identification of Metarhizium sp., and it was confirmed as $M$. anisopliae var. anisopliae by sequencing the ITS region (Internal Transcribed Spacers, ITS-5.8S rDNA). The two-phase culture was used for mass production. During the liquid phase, the isolated sample was taken from tubes and deposited in Petri dishes with an agar and sucrose medium enriched with Galleria mellonella Linnaeus 1758 (Riaz et al., 2013). The fungus was placed in the dishes and kept for $4 \mathrm{~d}$ in the incubation chamber at $25^{\circ} \mathrm{C}$ until fungus sporulation occurred. Conidial concentrations were determined by direct count with a Neubauer hemocytometer, and conidial viability tests were carried out (mean 97\%) using the methodology described by Moore et al. (1995). The conidial suspension was adjusted to $1 \times 10^{6}$ conidia $\mathrm{mL}^{-1}$ by diluting it with Tween $80(0.1 \% \mathrm{v} / \mathrm{v})$ (Garcia et al., 2005). A suspension with $1 \mathrm{~L}$ sterile distilled water, $1 \%$ Tween $80(0.1 \% \mathrm{v} / \mathrm{v}), 25 \mathrm{~g}$ yeast, and $20 \mathrm{~g}$ commercial sucrose was then prepared. It was deposited in $2 \mathrm{~L}$ jars that were autoclaved at $120{ }^{\circ} \mathrm{C}$ and 120 psi for $20 \mathrm{~min}$. Once the jars were cold, the inoculum was added and jars were connected to a ventilation system that oxygenated and agitated the suspension to form small mycelium pellets. After $3 \mathrm{~d}$, the solid phase began with substrate preparation.

Two substrates were used for the trials, new parboiled rice $(N P R)$ and recycled parboiled rice (RPR). The
RPR was recycled from a previous production of $M$. anisopliae, and it was harvested dry and washed with water three times. Both substrates were submerged and drained to achieve a $40 \%$ moisture level. Polyethylene bags $(325 \times 435 \mathrm{~mm})$ with $500 \mathrm{~g}$ each of the substrates and two different levels of beet (Beta vulgaris L. subsp. vulgaris) molasses (Industria Azucarera Nacional S.A.) were sterilized (Kruger et al., 2014) and taken to a laminar flow chamber where they were inoculated with $10 \mathrm{~mL}$ liquid inoculum prepared as mentioned above. Bags were plugged with a ventilated cap to minimize contamination and allow passive aeration during growth and conidiogenesis. After inoculation, the bags were put in different production rooms. Room 1 was kept at $20 \pm 1{ }^{\circ} \mathrm{C}$ while Room 2 was kept at $25 \pm 1{ }^{\circ} \mathrm{C}$. Both rooms had air extraction systems to allow appropritate ventilation. When the conidium production process ended, bags were removed from the chambers and emptied onto trays that were placed in the drying room where they were kept at $25 \pm 1{ }^{\circ} \mathrm{C}$ and $50 \pm 5 \% \mathrm{RH}$ for $10 \mathrm{~d}$. To determine the production level, $1 \mathrm{~g}$ rice with conidia was taken and a suspension of $100 \mathrm{~mL}$ sterile distilled water and Tween $80(0.05 \% \mathrm{v} / \mathrm{v})$ was prepared. Conidia obtained from the suspension were counted and dilutions were prepared when necessary.

\section{Experimental design}

A completely randomized experimental design with a factorial model was used; this allows the study of three factors at two levels. The experimental unit was a $500 \mathrm{~g}$ bag of substrate inoculated with the fungus. Two solid substrates were used to mass produce the conidia, NPR and RPR (Table 1).

The information was collected with a replicated two-level factorial design. First, it was modeled by estimating the effective dispersion coefficients using the least squares method and then obtaining the model for central tendency. Both were contrasted by the halfnormal probability chart (Daniel, 1959) to construct the global model, which allows process optimization. To use the two-level factorial design and generate an orthogonal design matrix, it was necessary to codify variables according to the following transformation (Vergara et al., 2013):

$$
X_{i}=\frac{\text { unit variable }- \text { average variable }}{(\text { width of interval }) / 2}
$$

These variables were obtained through a $2^{3}$ factorial design with three replicates of each experiment for a total of 24 experiments by measuring each production.

Pepió and Polo (1999) estimated the effects of scattering and the variances associated with each treatment of the

Table 1. Variables and their levels for new parboiled rice and recycled parboiled rice.

\begin{tabular}{lcc}
\hline Variable & Low level $(-1)$ & High level $(+1)$ \\
\hline A. Temperature, ${ }^{\circ} \mathrm{C}$ & 22 & 25 \\
B. Time, d & 14 & 20 \\
C. Molasses, $\%$ & 5 & 10 \\
\hline
\end{tabular}


model. With the minimum quadratic estimators of the dispersion coefficients, estimation efficiency can be increased by a credible maximum for the estimators. The analysis of the impact location is not verified when the assumption of equal treatment variance is expressed by the linear model:

$$
Y_{i j}=m_{i}+\sigma_{i} \varepsilon_{i j}=\sum_{k=1}^{n} a_{i k} \beta_{k}+\sigma_{i} \varepsilon_{i j}, j=1,2, \ldots, r
$$

The theoretical development by Pepió and Polo (1999) improved the work done by Nair and Pregibon (1988) to model joint variability and central tendency of an industrial production process using a type $2^{\mathrm{p}}$ factorial design, which allows variables to consider two levels with a total of $n=2^{p}$ treatments or samples codified in the lines specified in the matrix design and replicated $r$ times.

Given that $m_{i}$ is the mean and $\sigma^{2}{ }_{i}$ is the variance of observations for the $i^{\text {th }}$ treatment ( $i^{\text {th }}$ line of the array design), the model connects the mean and the variance with the $\beta_{k}$ factors and their interactions through the location coefficients $\beta_{k}$ and dispersion $\theta_{k}$. This model allows expressing the responses and the sums of squared differences in terms of the coefficients. Inasmuch as the estimated location coefficients $\beta_{k}$ differ depending on whether the variances $\sigma^{2}{ }_{i}$ can be considered to be statistically the same or not, it is first necessary to estimate the dispersion coefficients and explore their significance.

\section{RESULTS AND DISCUSSION}

The predicted response along with the experimental data of both substrates that are shown in Tables 2 and 3 reveal a close relationship between values. The industrial yield of the fungus in all the treatments was greater than $1 \times$ $10^{9}$ conidia $\mathrm{g}^{-1}$ and this coincides with results reported by Barajas et al. (2010) for M. anisopliae and substrate (parboiled rice). However, Prakash et al. (2008) used an optimized fermentation process and harvested $5.275 \times 10^{10}$ conidia $\mathrm{g}^{-1}$ in rice substrate. Temperature plays a major role in conidial production of $M$. anisopliae in rice substrates, and a higher temperature $\left(25^{\circ} \mathrm{C}\right)$ allows obtaining more conidia than a lower temperature $\left(20^{\circ} \mathrm{C}\right)$.

The effects and interactions, with their respective standard error, were calculated for NPR. Calculations of effects and standard error for NPR and RPR are shown in Tables 2 and 3, respectively. By using the half-normal probability plot method (Daniel, 1959), it can be seen that there was no significant variable or interaction, $\mathrm{p}>0.05$; the variance of the treatments was therefore established as being constant (Figure 1).

Since the variance of the treatments in both trials was accepted as being constant, the behavior of the mean production of replicates was modeled. The effects and interactions were estimated with the results from the trials; by the half-normal probability plot method for NPR, it was observed that the temperature and time variables, and the temperature $\times$ molasses and temperature $\times$ time interactions were significant, $\mathrm{p}<0.05$ (Figure 2). For RPR, the significant variables were temperature and time whereas the time $\times$ molasses and temperature $\times$ time interactions were significant, $\mathrm{p}<0.05$ (Table 4 ).

The multiple regression model permits the estimation of industrial performance (conidial yield) based on the significant variables and interactions for NPR:

$\mathrm{Y}=1729286603.62+206182122.98$ temperature + 204774854.92 time +87404648.45 temperature $\times$ time - [3]

140184355.10 temperature $\times$ molasses

Since the molasses variable was not significant in the studied variation range, it was fixed at a low level $(5 \%)$

Table 2. Mean production values for each treatment and $\operatorname{lnXi}$ values for new parboiled rice.

\begin{tabular}{|c|c|c|c|c|c|c|c|c|}
\hline Temperature & Time & Molasses & R1 & $\mathrm{R} 2$ & R3 & $\mathrm{Y}$ & $\mathrm{Xi}$ & InXi \\
\hline & & & \multicolumn{4}{|c|}{ conidia $\mathrm{g}^{-1}$} & $\left(\text { conidia } g^{-1}\right)^{2}$ & \\
\hline-1 & -1 & -1 & $1.29 \times 10^{9}$ & $1.34 \times 10^{9}$ & $1.34 \times 10^{9}$ & $1.33 \times 10^{9}$ & $1.59 \times 10^{15}$ & 35.00 \\
\hline 1 & -1 & -1 & $1.93 \times 10^{9}$ & $1.85 \times 10^{9}$ & $1.85 \times 10^{9}$ & $1.88 \times 10^{9}$ & $4.39 \times 10^{15}$ & 36.02 \\
\hline-1 & 1 & -1 & $1.54 \times 10^{9}$ & $1.59 \times 10^{9}$ & $1.59 \times 10^{9}$ & $1.58 \times 10^{9}$ & $2.05 \times 10^{15}$ & 35.26 \\
\hline 1 & 1 & -1 & $2.56 \times 10^{9}$ & $2.33 \times 10^{9}$ & $2.33 \times 10^{9}$ & $2.41 \times 10^{9}$ & $3.38 \times 10^{16}$ & 38.06 \\
\hline-1 & -1 & 1 & $1.37 \times 10^{9}$ & $1.54 \times 10^{9}$ & $1.54 \times 10^{9}$ & $1.48 \times 10^{9}$ & $2.11 \times 10^{16}$ & 37.59 \\
\hline 1 & -1 & 1 & $1.41 \times 10^{9}$ & $1.40 \times 10^{9}$ & $1.40 \times 10^{9}$ & $1.41 \times 10^{9}$ & $5.78 \times 10^{13}$ & 31.69 \\
\hline-1 & 1 & 1 & $1.71 \times 10^{9}$ & $1.70 \times 10^{9}$ & $1.70 \times 10^{9}$ & $1.70 \times 10^{9}$ & $6.74 \times 10^{13}$ & 31.84 \\
\hline 1 & 1 & 1 & $1.98 \times 10^{9}$ & $2.08 \times 10^{9}$ & $2.08 \times 10^{9}$ & $2.05 \times 10^{9}$ & $6.44 \times 10^{15}$ & 36.40 \\
\hline
\end{tabular}

R1-R3: Conidial yield for each replicate, Y: mean conidial yield, Xi: variance numerator ((n - 1)S $\left.\mathrm{S}^{2}\right)$.

Table 3. Mean production values for each treatment and $\operatorname{lnXi}$ values for recycled parboiled rice.

\begin{tabular}{|c|c|c|c|c|c|c|c|c|}
\hline Temperature & Time & Molasses & R1 & R2 & R3 & $\mathrm{Y}$ & $\mathrm{Xi}$ & InXi \\
\hline & & & \multicolumn{4}{|c|}{$\longrightarrow$ conidia $g^{-1} \longrightarrow$} & $\left(\text { conidia }^{-1}\right)^{2}$ & \\
\hline-1 & -1 & -1 & $1.68 \times 10^{9}$ & $1.05 \times 10^{9}$ & $1.45 \times 10^{9}$ & $1.40 \times 10^{9}$ & $2.07 \times 10^{17}$ & 39.87 \\
\hline 1 & -1 & -1 & $1.53 \times 10^{9}$ & $2.02 \times 10^{9}$ & $2.21 \times 10^{9}$ & $1.92 \times 10^{9}$ & $2.45 \times 10^{17}$ & 40.04 \\
\hline-1 & 1 & -1 & $1.58 \times 10^{9}$ & $1.90 \times 10^{9}$ & $1.88 \times 10^{9}$ & $1.79 \times 10^{9}$ & $6.54 \times 10^{16}$ & 38.72 \\
\hline 1 & 1 & -1 & $2.57 \times 10^{9}$ & $2.67 \times 10^{9}$ & $2.77 \times 10^{9}$ & $2.67 \times 10^{9}$ & $1.90 \times 10^{16}$ & 37.48 \\
\hline-1 & -1 & 1 & $2.42 \times 10^{9}$ & $1.65 \times 10^{9}$ & $2.28 \times 10^{9}$ & $2.11 \times 10^{9}$ & $3.33 \times 10^{17}$ & 40.35 \\
\hline 1 & -1 & 1 & $2.08 \times 10^{9}$ & $2.27 \times 10^{9}$ & $2.09 \times 10^{9}$ & $2.15 \times 10^{9}$ & $2.24 \times 10^{16}$ & 37.65 \\
\hline-1 & 1 & 1 & $1.51 \times 10^{9}$ & $1.67 \times 10^{9}$ & $1.50 \times 10^{9}$ & $1.56 \times 10^{9}$ & $1.97 \times 10^{16}$ & 37.52 \\
\hline 1 & 1 & 1 & $2.20 \times 10^{9}$ & $2.61 \times 10^{9}$ & $2.20 \times 10^{9}$ & $2.34 \times 10^{9}$ & $1.11 \times 10^{17}$ & 39.25 \\
\hline
\end{tabular}

R1-R3: Conidial yield for each replicate, Y: mean conidial yield, Xi: variance numerator ((n - 1)S $\left.{ }^{2}\right)$. 
Figure 1. Half-normal chart of $\mathrm{LnXi}$ effects for new parboiled rice (NPR) (a) and recycled parboiled rice (RPR) (b).
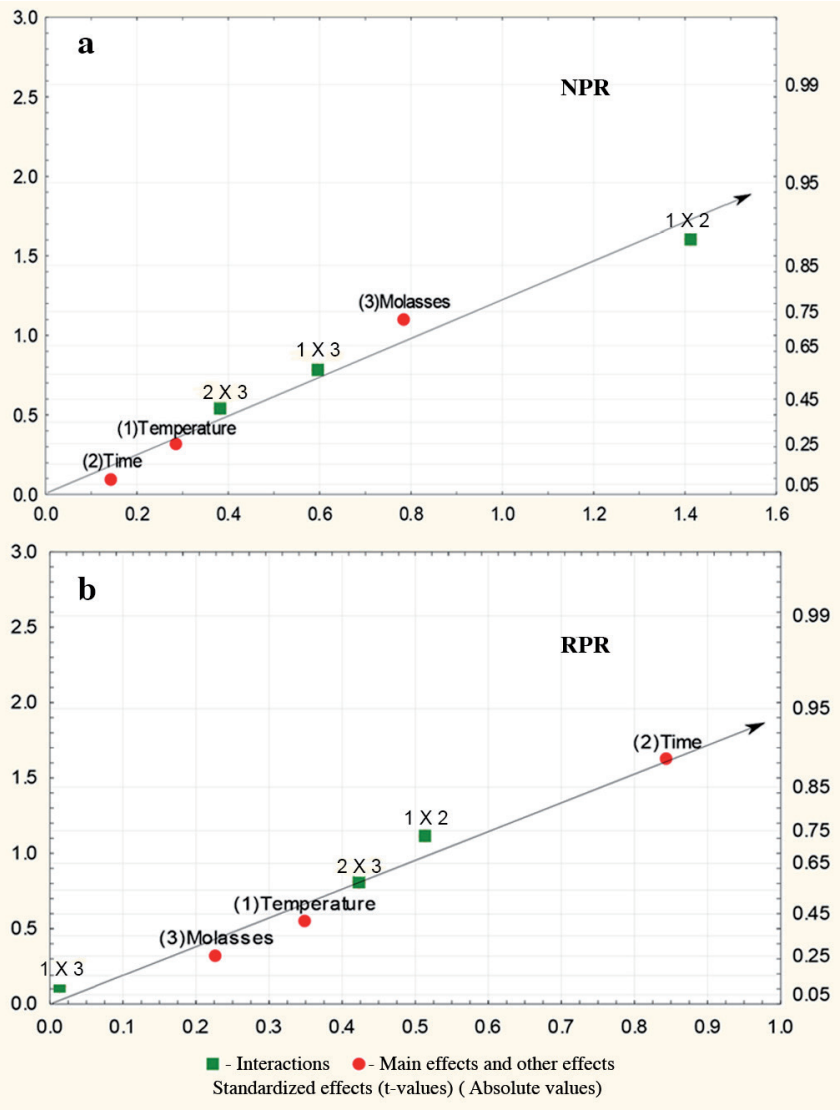

which reduces costs. The reduced model for NPR can be expressed as:

$\mathrm{Y}=1729286603.62+206182122.98$ temperature + 204774854.92 time +87404648.45 temperature $\times$ time [4]

The chart for the NPR response surface in Figure 3 shows that most of the estimated $M$. anisopliae production with a low level of molasses (-1), $5 \%$, can be obtained by setting temperature and time to a high level with values close to $2.4 \times 10^{9}$ conidia $\mathrm{g}^{-1}$; these results were higher than those obtained by Kruger et al. (2014) and Latifian et al. (2014), thus demonstrating process efficiency. In the corresponding contour plot, each line represents the same production at different levels of the significant variables. When setting the concentration of molasses to a high level $(+1), 10 \%$, most of the estimated conidial production was produced when temperature and time were set to a high level with values close to $2.1 \times 10^{9}$ conidia g $^{-1}$ (Figure 4 ). Setting the amount of molasses to a low level decreased the process costs (-1). Results partly agree with observations by Karanja et al. (2010), who demonstrated that maximum yield was achieved when fungi were grown on rice at $23^{\circ} \mathrm{C}$ for $3 \mathrm{wk}$.

The multiple regression model permits the estimation of the industrial performance of $M$. anisopliae based on the significant variables and interactions for RPR:

$\mathrm{Y}=1991978528.77+277452488.97$ temperature +

97160190.83 time +137180650.84 temperature $\times$ time -188641698.72 time $\times$ molasses
Figure 2. Half-normal chart of effects for new parboiled rice (NPR) (a) and recycled parboiled rice (RPR) (b).
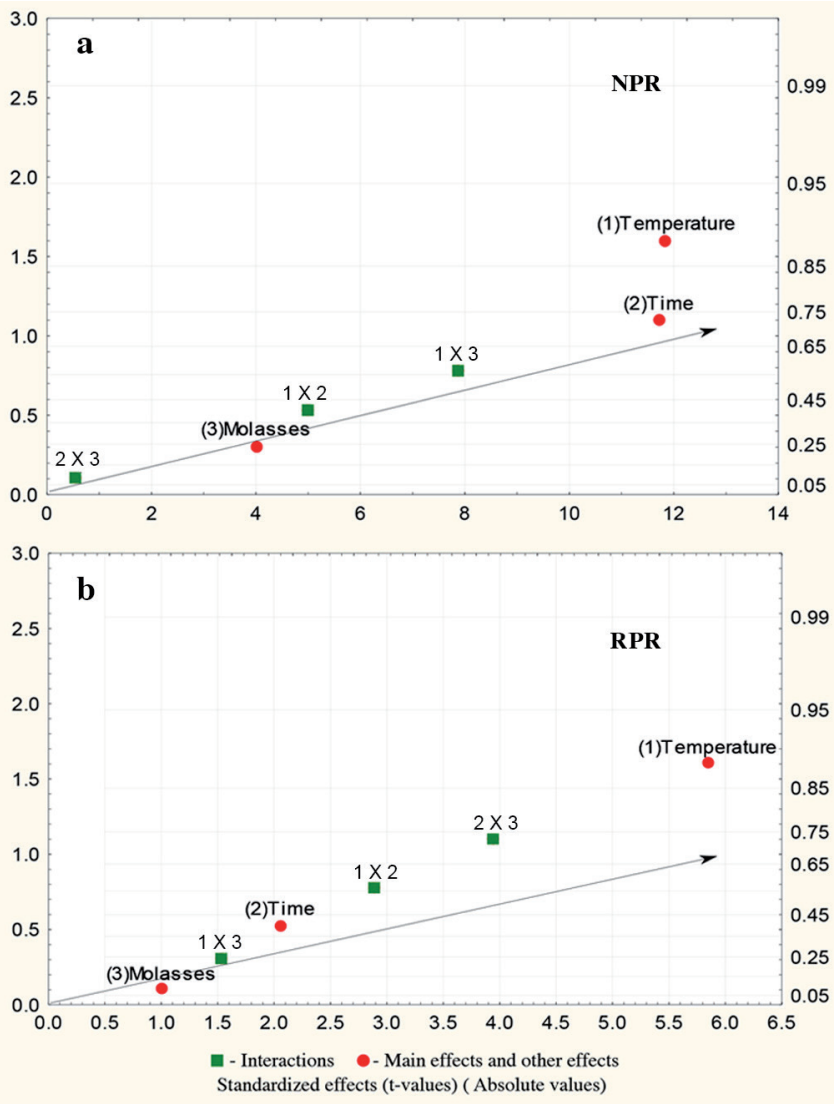

Since the molasses variable was not significant in the studied variation range, it was fixed at a low level $(5 \%)$ which reduces costs. The reduced model for RPR can be expressed as:

$$
\begin{gathered}
\mathrm{Y}=1991978528.77+277452488.97 \text { temperature }+ \\
97160190.83 \text { time }+ \\
137180650.84 \text { temperature } \times \text { time }
\end{gathered}
$$

For RPR, the results of the response surfaces (Figures 5 and 6$)$ revealed the best industrial performance at 2.7 $\times 10^{9}$ conidia $\mathrm{g}^{-1}$; the highest levels of the temperature $\left(25^{\circ} \mathrm{C}\right)$ and time $(20 \mathrm{~d})$ variables must be used while the nonrelevant molasses variable can be set at the lowest level to decrease process costs. These results were higher than those obtained by Babu et al. (2008). The higher production, compared with NPR, could be explained by the fact that RPR was more fragmented and had a larger surface area for conidial formation; this was indicated by Kruger et al. (2014)

Table 4. Regression coefficients and significant variables and interactions of new parboiled rice (NPR) and recycled parboiled rice $(\mathbf{R P R})$

\begin{tabular}{lcc}
\hline Variables & $\begin{array}{c}\text { Regression coefficient } \\
\text { NPR }\end{array}$ & $\begin{array}{c}\text { Regression coefficient } \\
\text { RPR }\end{array}$ \\
\hline Interaction mean & $1.73 \times 10^{9}$ & $1.99 \times 10^{9}$ \\
Temperature & $2.06 \times 10^{8}$ & $2.77 \times 10^{8}$ \\
Time & $2.05 \times 10^{8}$ & $9.72 \times 10^{7}$ \\
Temperature $\times$ Time & $8.74 \times 10^{7}$ & $1.37 \times 10^{8}$ \\
Temperature $\times$ Molasses & $-1.40 \times 10^{8}$ & - \\
Time $\times$ Molasses & - & $-1.89 \times 10^{8}$ \\
\hline
\end{tabular}


Figure 3. 3-D response surface plot (a) and contour plot (b) by monitoring temperature, time, and setting molasses to level -1 (5\%) for Metarhizium anisopliae conidial production in solidstate fermentation using new parboiled rice as substrate.

a

b
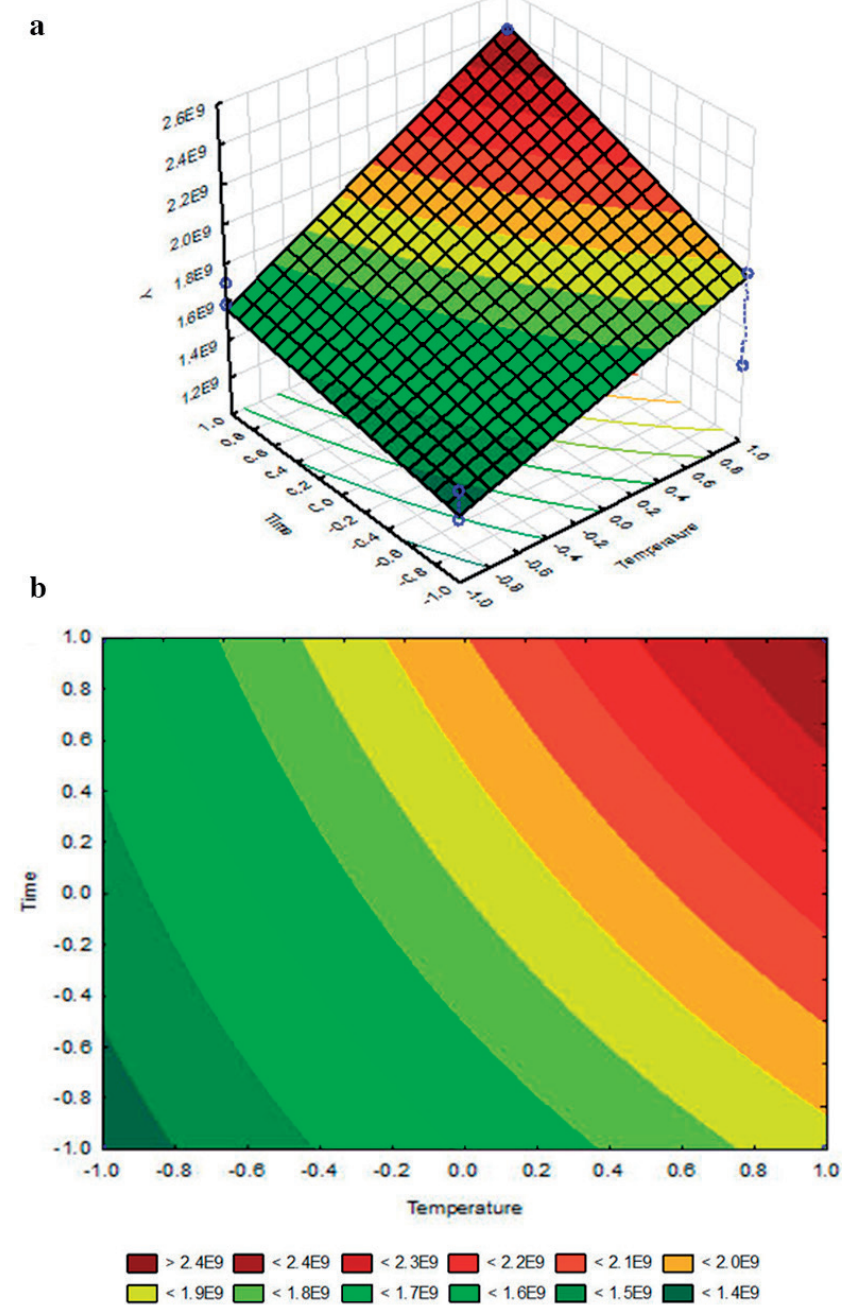

in a study where broken white rice exhibited the highest production $\left(3.7 \times 10^{9}\right.$ conidia $\left.^{-1}\right)$. It can also be that broken rice has better aeration along with this increased surface area or that rice was internally softer, which provides a better supply of nutrients.

The substrates used in the present study had the highest production of conidia per gram; this was better than results obtained by Ibrahim et al. (2015) with a shorter drying time (1 wk less) and demonstrates that the process was more efficient and could significantly reduce production costs. Although the $20 \mathrm{~d}$ cycle resulted in higher production than the $14 \mathrm{~d}$ cycle, short cycles would allow more production runs in a year, 26 and 18 cycles per year, respectively; if capital costs are taken into account, the economic results might be better. Temperatures proved to be a significant variable in both substrates with $25^{\circ} \mathrm{C}$ being the optimum temperature to achieve high levels of conidial production; and this result agrees with Lu et al. (2004).
Figure 4. 3-D response surface plot (a) and contour plot (b) by monitoring temperature, time, and setting molasses to level +1 (10\%) for Metarhizium anisopliae conidial production in solidstate fermentation using new parboiled rice as substrate.

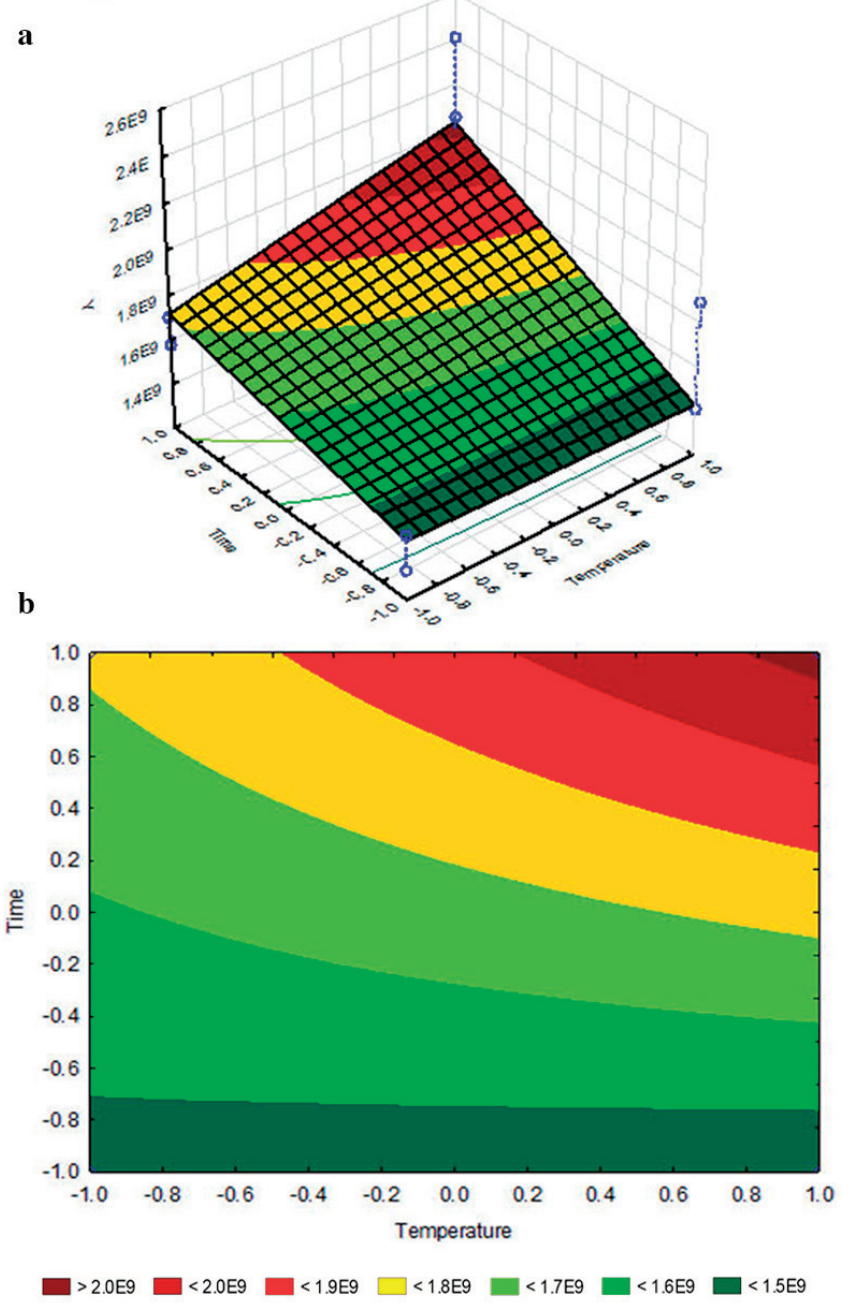

\section{CONCLUSIONS}

Based on the results, it was concluded that the response surface methodology allows optimizing the mass production of Metarhizium anisopliae. The optimal combination of the studied variables was $25^{\circ} \mathrm{C}$ and $20 \mathrm{~d}$, regardless of the level of molasses. Therefore, it is recommended that $5 \%$ molasses should be used to decrease production costs. This combination was the same for both substrates in the present study. The mean industrial performance for the new parboiled rice substrate and for the recycled parboiled

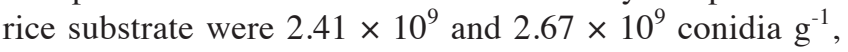
respectively, which is higher than the mean obtained for $M$. anisopliae $\left(1 \times 10^{9}\right.$ conidia $\left.\mathrm{g}^{-1}\right)$. Finally, it is possible to use the recycled rice substrate from the $M$. anisopliae production itself as an alternative for solid substrate, thus obtaining a higher mean industrial performance (conidia $\mathrm{g}^{-1}$ ) than when using new parboiled rice, and this will reduce the production costs of this entomopathogenic fungus. 
Figure 5.3-D response surface plot (a) and contour plot (b) by monitoring temperature, time, and setting molasses to level -1 (5\%) for Metarhizium anisopliae conidial production in solidstate fermentation using recycled parboiled rice as substrate.

$\mathbf{a}$
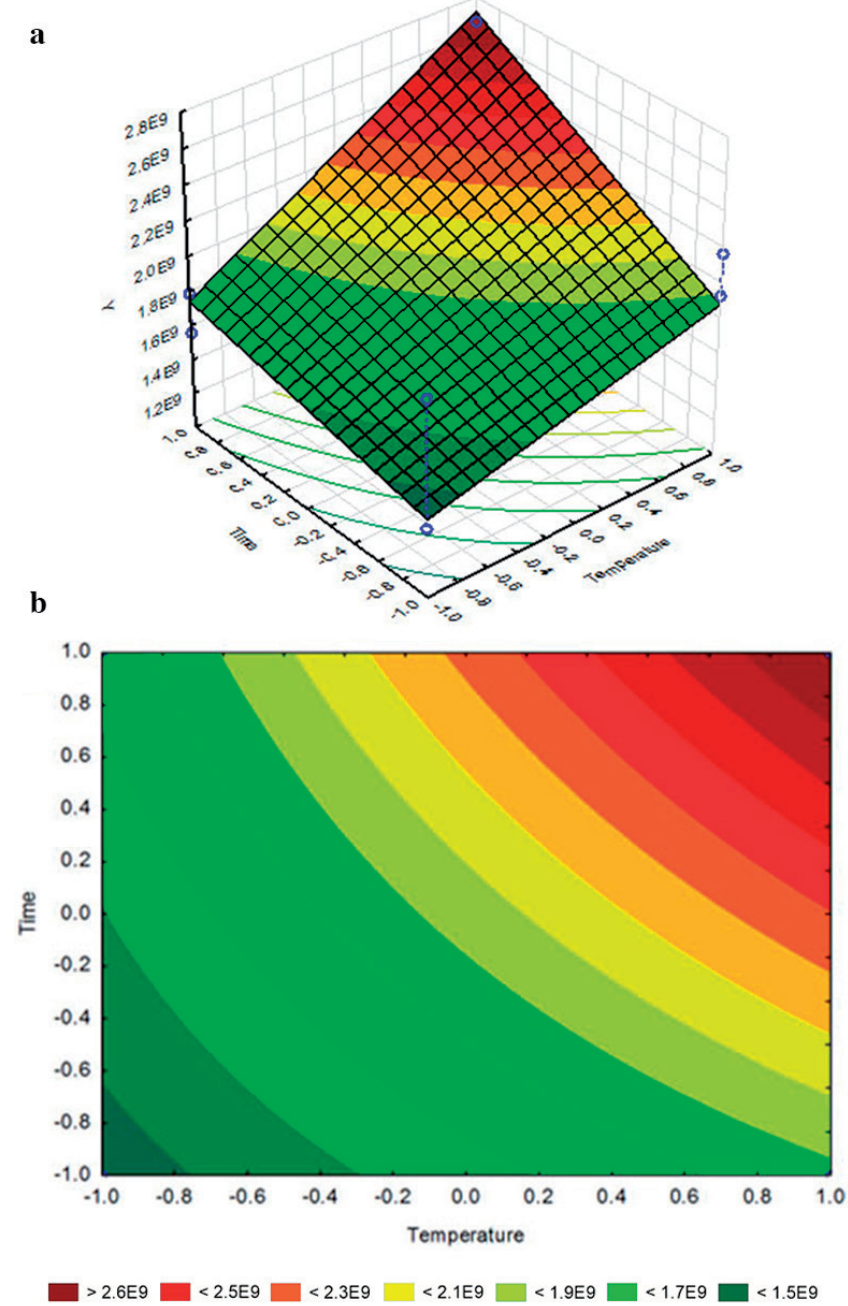

\section{REFERENCES}

Arzumanov, T., N. Jenkins, and S. Roussos. 2005. Effect of aeration and substrate moisture content on sporulation of Metarhizium anisopliae var. acridum. Process Biochemistry 40(3/4):1037-1043.

Babu, J., C.M. Venkatachalapathy, and C.N. Anitha. 2008. Evaluation of locally available substrates for mass multiplication of entomopathogenic fungi, Metarhizium anisopliae (Metch.) Sorokin. Journal of Invertebrate Pathology 46:335-336.

Barajas, C., E. del Pozo, I. García, y A. Méndez. 2010. Obtención de conidios del aislamiento MA-002 de Metarhizium anisopliae (Metsch.) Sorokin mediante una alternativa de cultivo bifásico. Revista de Protección Vegetal 25(3):174-180.

Beys-da-Silva, W.O., L. Santi, M. Berger, D. Calzolari, D.O. Passos, J.A. Guimarães, et al. 2014. Secretome of the biocontrol agent Metarhizium anisopliae induced by the cuticle of the cotton pest Dysdercus peruvianus reveals new insights into infection. Journal of Proteome Research 13(5):2282-2296. http://doi.org/10.1021/pr401204y.
Figure 6. 3-D response surface plot (a) and contour plot (b) by monitoring temperature, time, and setting molasses to level +1 (10\%) for Metarhizium anisopliae conidial production in solidstate fermentation using recycled parboiled rice as substrate.
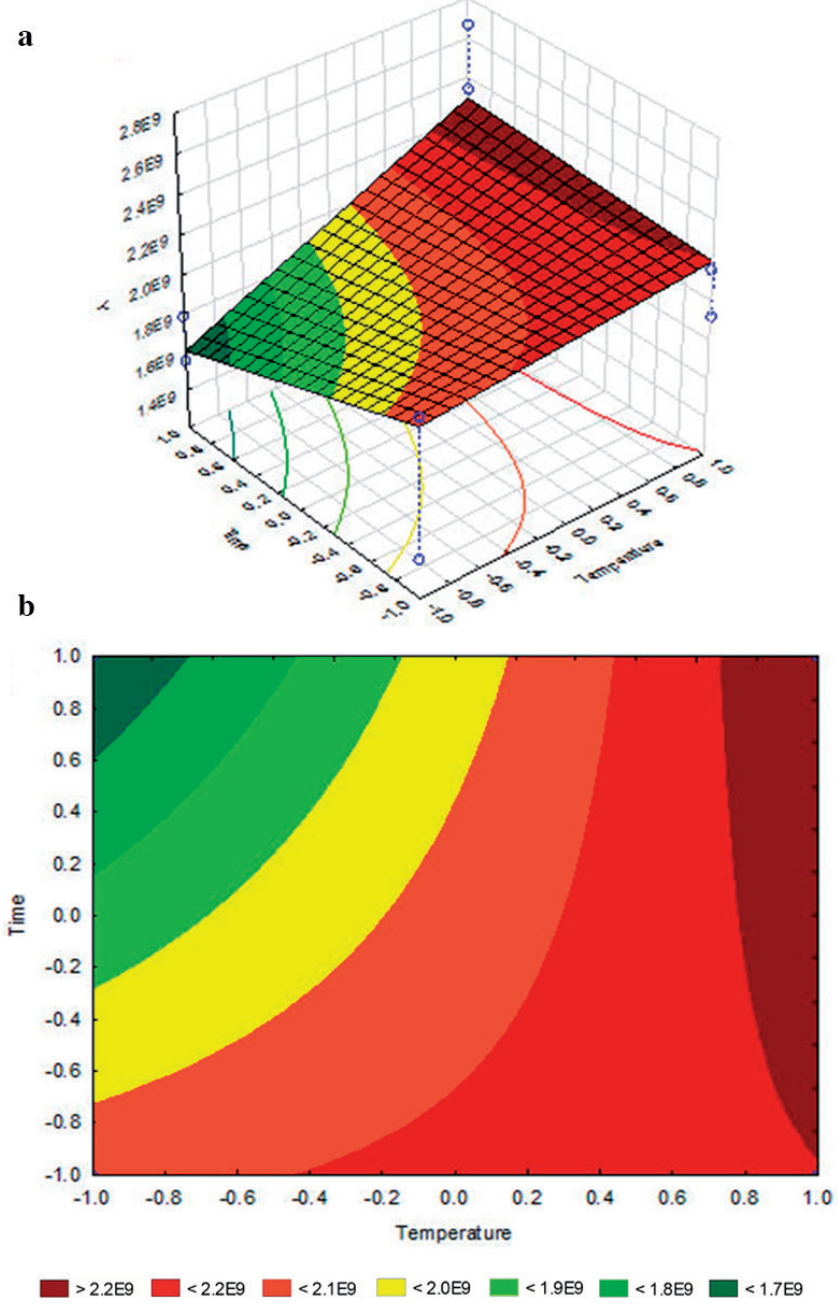

Chen, Z.H., L. Xu, F.L. Yang, G.H. Ji, J. Yang, and J.Y. Wang. 2014. Efficacy of Metarhizium anisopliae isolate MAX-2 from Shangrila, China under desiccation stress. BMC Microbiology 14:4.

Daniel, C. 1959. Use of half normal probability plots in interpreting factorial two-level experiments. Technometrics 1(4):311-341.

Dorta, B., y J. Arcas. 1998. La esporulación de Metarhizium en fermentación en estado sólido con aireación forzada. Enzyme and Microbial Technology 23:501-505.

Elósegui, O. 2006. Métodos artesanales de producción de bioplaguicidas a partir de hongos entomopatógenos y antagonistas. 61 p. Instituto de Investigaciones de Sanidad Vegetal (INISAV), La Habana, Cuba.

France, A., M. Gerding G., M. Gerding P., y A. Sandoval. 2000. Patogenicidad de una colección de cepas nativas de Metarhizium spp. y Beauveria spp. en Aegorhinus superciliosus, Asynonychus cervinus, Otiorhynchus sulcatus. Agricultura Tecnica 60:205-215.

Garcia, M.V., A.C. Monteiro, M.J.P. Szabo, N. Prette, and G.H. Bechara. 2005. Mechanism of infection and colonization of Rhipicephalus sanguineus eggs by Mertarhizium anisopliae as revealed by scanning eletron microscopy and histopathology. Brazilian Journal of Microbiology 36(4):368-372. 
Gohel, V., T. Chaudhary, P. Vyas, and H.S. Chhatpar. 2006. Statistical screenings of medium components for the production of chitinase by the marine isolate Pantoea dispersa. Biochemical Engineering Journal 28(1):50-56.

Freimoser, F.M., G. Hu, and R.J. St. Leger. 2005. Variation in gene expression patterns as the insect pathogen Metarhizium anisopliae adapts to different host cuticles or nutrient deprivation in vitro. Microbiology 151:361-371.

Hanrahan, G., and K. Lu. 2006. Application of factorial designs and response surface methodology in modern experimental design and optimization. Critical Reviews in Analytical Chemistry 36:141-151.

Ibrahim, L., L. Laham, A. Touma, and S. Ibrahim. 2015. Mass production, yield, quality, formulation and efficacy of entomopathogenic Metarhizium anisopliae conidia. British Journal of Applied Science and Technology 9(5):427-440.

Jenkins, N.E., G. Heviefo, J. Langewald, A.J. Cherry, and C.J. Lomer. 1998. Development of mass production technology for aerial conidia for use as mycopesticides. Biocontrol News and Information 19:21N-32N.

Karanja, L.W., N.A. Phiri, and G.I. Oduor. 2010. Effect of different solid substrates on mass production of Beauveria bassiana and Metarhizium anisopliae entomopathogens. p. 8-12. $12^{\text {th }}$ KARI Biennial Scientific Conference, Nairobi, Kenya.

Kassa, A., M. Brownbridge, B.L. Parker, M. Skinner, V. Gouli, S. Gouli, et al. 2008. Whey for mass production of Beauveria bassiana and Metarhizium anisopliae. Mycological Research 112(5):583-591

Kleespies, R.G., and G. Zimmermann. 1992. Production of blastospores by three strains of Metarhizium anisopliae (Metch.) Sorokin in submerged culture. Biocontrol Science and Technology 2(2):127-135.

Kruger, R.D., J.B. Posadas, M.A. Lewylle, J.I. Mini, and R.E. Lecuona. 2014. Solid substrate production and formulation of an isolate of Metarhizium anisopliae for biological control of stem bug Tibraca limbativentris. World Applied Sciences Journal 32(7):1242-1251.

Latifian, M., B. Rad, and M. Amani. 2014. Mass production of entomopathogenic fungi Metarhizium anisopliae by using agricultural products based on liquid-solid diphasic method for date palm pest control. International Journal of Farming and Allied Sciences 3(4):368-372.

Li, J., and M.G. Feng. 2009. Intraspecific tolerance of Metarhizium anisopliae conidia to the upper thermal limits of summer with a description of a quantitative assay system. Mycological Research 113(1):93-99. doi:10.1016/j. mycres.2008.08.006.

Lu, Z.Y., S. Gao, and Y. Jiang. 2004. Screening of solid cultural condition for Metarhizium anisopliae. Chinese Journal of Applied and Environmental Biology 10:223-225.
Moore, D., R.P. Bateman, M. Carey, and C. Prior. 1995. Long-term storage of Metarhizium flavoviride conidia in oil formulations for the control of locusts and grasshoppers. Biocontrol Science and Technology 5(2):193-200.

Nair, V., and D. Pregibon 1988. Analyzing dispersion effects from replicated factorial experiments. Technometrics 30(3):247-257.

Pepió, M., and C. Polo. 1999. Design and optimization of process. Statistical Laboratory. Escuela Técnica Superior de Ingeniería Industrial de Barcelona (ETSEIB) - Universidad Politécnica de Cataluña (UPC), Barcelona, Spain.

Pereira, R., and D. Roberts. 1990. Dry mycelium preparations of entomopathogenic fungi, Metarhizium anisopliae and Beauveria bassiana. Journal of Invertebrate Pathology 55:39-46.

Prakash, G.B., V. Padmaja, and R.S. Kiran. 2008. Statistical optimization of process variables for the large-scale production of Metarhizium anisopliae conidiospores in solid-state fermentation. Bioresource Technology 99(6):1530-1537.

Rezende, J. 2009. Influencia de las calidades de distintos tipos de arroz e inhibidores de proteinasas en el rendimiento y virulencia de conidio de hongo entomopatógeno Metarhizium anisopliae. Trabajo para obtener el título de Máster en Ciencias. Universidad de São Paulo, São Paulo, Brasil.

Riaz, A.B.I.D., F.A. Shah, and T.M. Butt. 2013. Intra-specific variability among Metarhizium anisopliae strains in their ability to produce blastospores in liquid culture media. Pakistan Journal of Botany 45(3): 1099-1103.

Samson, R.A., H.C. Evans, and J.P. Latgé. 2013. Atlas of entomopathogenic fungi. Springer Science \& Business Media, Berlin, Heidelberg, Germany.

Schneider, L.C.L., C.V. Silva, J.A. Pamphile, and H. Conte. 2013. Infection, colonization and extrusion of Metarhizium anisopliae (Metsch) Sorokin (Deuteromycotina: Hyphomycetes) in pupae of Diatraea saccharalis F. (Lepidoptera: Crambidae). Journal of Entomology and Nematology 5(1):1-9.

Vergara, P., E. Uribe, and A. Cortés. 2013. Optimization of a quality model for CCA industrial impregnation of Pinus radiata $\mathrm{D}$. Don agricultural fencing stakes. Wood Research 58(1):131-140

Wraight, S.P., M.A. Jackson, and S.L. De Kock. 2001. Production, stabilization and formulation of fungal biocontrol agents. In Butt, T.M., C. Jackson, and N. Magan (eds.) Fungi as biocontrol agents: Progress, problems and potential. Publishing CAB International, London, UK. 